\title{
Trajetória de herdeiro entre dois projetos políticos
}

Agueda Bernardete Bittencourt

Universidade Estadual de Campinas

\section{Resumo}

A trajetória intelectual e social do educador Anísio Teixeira é estudada neste artigo considerando suas origens geográficas na Bahia - estado politicamente periférico em relação a outros da federação brasileira situados no sudeste e sul -, bem como suas origens sociais, que não o predestinavam a jogar um papel de primeiro plano na cena nacional, muito menos antes de completar 40 anos. Uma série de documentos com registros de suas viagens internacionais permite aqui a análise dos momentos-chave de suas primeiras coletas de informações sobre o tema da educação e o uso que fez dos seus contatos com intelectuais e políticos em instituições de ponta na Europa e Estados Unidos, visando o desenho de um projeto brasileiro de Educação num momento de transição política, ou seja, o período 1925 a 1934. Com ênfase nos encontros de Anísio Teixeira com intelectuais fascistas na ltália e França e com os proponentes da educação democrática nos Estados Unidos, o artigo está voltado para mostrar também como essas viagens permitiram a redefinição da carreira em função de bloqueio dado pela revolução ao destino que sua educação familiar the projetara. Aproximações e articulações do grupo baiano com intelectuais paulistas na capital da República encarregaram-se de reposicionar o herdeiro em sua trajetória de homem político.

\section{Palavras-chave}

Circulação internacional - Educação brasileira - Formação de elite - Intelectuais brasileiros - Anísio Teixeira. 


\title{
Trajectory of an heir between two political projects
}

Agueda Bernardete Bittencourt

Universidade Estadual de Campinas

\begin{abstract}
The intellectual and social trajectory of educator Anisio Teixeira is investigated in this article considering his geographical origins in Bahia - a politically peripheral state in relation to other states of the Brazilian federation of the Southeast and South regions -, as well as his social origins, which did not predestined him to a prominent role in the national scene, even less before being forty years old. A series of documents recording his international visits makes it possible here to analyze the key moments of his first information gathering about the issue of education, and the use he made of his contacts with intellectuals and politicians in first-rate European and American institutions with the purpose of conceiving a Brazilian project for Education in a moment of political transition, that is, in the 1925-1934 period. Emphasizing his meetings with fascist intellectuals in Italy and France, and with proponents of democratic education in the United States of America, the article attempts to show also how these trips allowed him to redefine his career in view of the obstacles erected by the revolution in the path his family education had foreseen for him. Approximations and articulations of the Bahia group with São Paulo intellectuals in the Capital of the Republic took care of repositioning the heir in his trajectory as a man of politics.
\end{abstract}

\section{Keywords}

International circulation - Brazilian education - Elite formation Brazilian intellectuals - Anísio Teixeira.

\footnotetext{
Contact:

Agueda Bernardete Bittencourt

Rua Coronel Quirino, 380, apto. 63

13025-000 - Campinas - SP

e-mail: agueda.bittencourt@gmail.com
} 
A historiografia educacional brasileira ressalta a figura de Anísio Teixeira como a de um grande inovador do sistema escolar. Sua presença na luta pela institucionalização de um projeto nacional de Educação deu lugar a muitos escritos e polêmicas, em especial voltados aos aspectos técnicos, administrativos e de políticas públicas em sua carreira. Ele esteve comprometido, entre outras, com a reorganização e desenvolvimento do Instituto Nacional de Estudos Pedagógicos - INEP -; com a criação do Centro Brasileiro de Pesquisa Educacional e seus Centros Regionais; da Coordenação de Aperfeiçoamento de Professores para o Ensino Superior CAPES -; da Universidade de Brasília, sendo o criador desta; e signatário do Manifesto dos Pioneiros da Educação Nova na década de 1930.

Uma série de documentos com registros de suas viagens internacionais abre margem para rever os momentos-chave de suas primeiras coletas de informações sobre o tema e o uso que fez dos seus contatos com intelectuais e políticos em instituições de ponta na Europa e Estados Unidos ${ }^{1}$, visando o desenho de um projeto brasileiro de Educação num momento de transição política, ou seja, o período 1925 a $1934^{2}$. Trata-se de um período em que as críticas às instituições brasileiras se tornaram violentas e culminaram no golpe de Estado de 1930, conhecido na história oficial como Revolução de 30. Os primeiros anos dessa década assinalam uma série de inovações no país, que partem do Executivo, entre elas a criação do Ministério da Educação e Saúde. Com ênfase nos encontros de Anísio Teixeira com intelectuais fascistas na Itália e França e com os proponentes da educação democrática nos Estados Unidos, o artigo está voltado para mostrar também como essas viagens permitiram a redefinição da carreira em função de bloqueio dado pela revolução ao destino que sua educação familiar lhe projetara ${ }^{3}$.

\section{Anísio Teixeira: um filho do sertão baiano}

A trajetória intelectual e social do educador Anísio Teixeira é extremamente relevante, porque suas origens geográficas na Bahia - estado politicamente periférico em relação a outros da federação brasileira situados no sudeste e sul -, bem como suas origens sociais, não o predestinavam a jogar um papel de primeiro plano na cena nacional, muito menos antes de completar 40 anos.

Anísio Teixeira é o oitavo filho do médico Deocleciano Pires Teixeira. Embora descendente de um capitão $\mathrm{mor}^{4}$, seu pai pertencia a uma camada social dominante instável, porque de mineradores e comerciantes de diamantes. Foram as alianças endogâmicas com três irmãs herdeiras de vasta extensão de terra do sertão baiano que lhes permitiram a segurança para seguir os aleatórios caminhos da política regional, transformando-se em

[...] prestigioso chefe político, figura quase legendária de respeitado líder sertanejo, de sólida fé republicana, no melhor estilo patriarcalista. (Lima, 1978, p. 16)

A mãe de Anísio era Anna de Souza Spínola, do terceiro matrimônio de Deocleciano dentro da Família Spínola. Esses fatos o situam dentro de uma realidade comum aos membros da elite rural brasileira, na qual a persistência de casamentos consanguíneos se explica pelo interesse na manutenção de um patrimônio tanto econômico quanto político. 0 Dr. Deocleciano foi, assim, presidente do Conselho Municipal de Caetité, cidade onde vivia com a família, e deputado provincial nas fi-

1. Os estudos produzidos no Centre de la Recherche sur le Brésil Contemporain e a sociologia produzida no Centre de Sociologia européenne - EHESS -, dentro de um programa proposto por Pierre Bourdieu nos anos 1990, é o ponto de referência deste trabalho. Essa sociologia vem tratando dos valores e das ideias que circulam por meio das trocas internacionais estabelecidas pelos intelectuais como se pode observar em Actes de la recherche en sciences sociales (Les ruses de la raison impérialiste, 1998; La circulation internationale des idées, 2002b; Sociologie de la mondialisation, 2004; Cahiers du Brésil Contemporain, 2004-2005).

2. Esta pesquisa insere-se em um projeto maior voltado ao significado da circulação internacional na recomposição das elites brasileiras financiado pela FAPESP.

3. Ver sobre o mesmo assunto, no Cahiers de la recherche sur l'education et les savoirs (2009), o artigo: Anisio Teixeira: origines internationales d'un nationalisme pédagogique.

4. Os capitães, no período colonial brasileiro, eram nomeados pelo governo português a partir de uma lista de três nomes apresentados pelo conselho municipal. Eram designados "com base na nobreza e riqueza". 
leiras do Partido Liberal no final do Império. No início do período republicano, chegou a ser eleito senador estadual.

Caetité situa-se na divisa com Minas Gerais em região célebre pela produção de cacau. Desse local, Deocleciano reparava as alianças políticas que se partiam nas lutas de família do sertão e nas disputas pelo poder com as regiões produtoras de açúcar e com o comércio litorâneo da grande Salvador (Lima, 1978).

Os proprietários de terra, chefes sertanejos, eram aqueles que, em troca de favores (construção de estradas, nomeação de delegado de polícia etc.) compunham com os chefes regionais a sustentação da oligarquia no poder, ou melhor, eram os agentes ativos na eleição dos deputados estaduais indicados, os quais eram elementos-chave na defesa dos interesses baianos na esfera federal (Pang, 1979). Isso porque, dentro da "política dos governadores”, idealizada no começo da República, o presidente da República estabelecia os acordos com os presidentes dos estados federados de maneira a obter o total apoio de todos os seus atos: os presidentes dos estados apoiariam o da República, bem como levariam consigo os senadores obedientes às suas ordens. Não é surpreendente, portanto, que os filhos dos chefes regionais devessem ser preparados desde muito cedo para o destino político que a família lhes reservava.

Os dez filhos de Deocleciano foram educados conforme as necessidades impostas por essa engrenagem política e pela tradição de família de mineradores. Com exceção de Anísio que era advogado, todos os demais eram engenheiros e ocuparam cargos políticos como de deputado estadual ou chefe local e cargos burocráticos na máquina do estado (Pang, 1979; Lima, 1978).

Quanto às suas quatro filhas, cumpriram o destino feminino, importante para manutenção do lugar social da família de políticos. Uma se casou e a outra, Carmem S. Teixeira, dedicou sua vida ao projeto educacional de seu irmão na Bahia. As outras duas dedicaram-se à administração do casarão e às obras de caridade associadas ao nome da família.
Outros membros da família já haviam ocupado importantes postos políticos. Antonio de Souza Spínola, avô de Anísio Teixeira, foi representante de seu distrito na Assembleia Provincial e no Parlamento Monárquico. Cesar Zama, primo de Anísio, foi deputado por 24 anos na Assembleia Nacional do Império e deputado constituinte da República.

Foi nesse ambiente político e social que se deu a educação de Anísio Teixeira, escalado, entre os irmãos, para substituir o pai, quando este deixasse a política.

\section{O herdeiro diante de dois projetos em disputa}

Os estudos de Anísio Teixeira até os 15 anos desenrolaram-se em colégios internos jesuítas. Dessa experiência, adveio-lhe a ideia de uma carreira religiosa, sonho que acalentou durante toda a sua estada em Salvador e no Rio de Janeiro enquanto fazia o curso de Direito. Uma forte oposição a esse projeto veio da família paterna, que pretendia encaminhá-lo à magistratura no intuito de galgá-lo aos altos cargos no Estado. 0 apoio ao plano religioso veio do lado materno que, por sua vez, vislumbrava para ele uma carreira promissora na missionária Companhia de Jesus.

0 primeiro lance da disputa foi dado pela família paterna ao enviá-lo para a Faculdade de Direito no Rio de Janeiro, onde se diplomou em 1922. Ai viveu na companhia do tio paterno, funcionário da alfândega, que estudara inglês e contabilidade na Inglaterra, preparando-se para suceder seu pai no comércio de diamantes.

Em sua volta à Bahia como bacharel, aos 23 anos, foi indicado inspetor geral do ensino, apontado pelos chefes sertanejos em troca do apoio à eleição do oligarca Francisco Marques de Góis Calmon, encarregado de derrotar os adversários na região do cacau. Esse cargo era de alta visibilidade, configurando sua entrada na vida política. Sobre o fato, Oscar S. Teixeira (apud Pereira Guimarães, 1982) escreveu: 
0 meu irmão Anísio, hoje Inspetor do Ensino, goza de toda a confiança do Governador e representa hoje a política deste sertão, em substituição a meu Pai que, desgostoso com a solução de certos casos aqui, se afastou da atividade política. ${ }^{5}$

No entanto, são as três viagens realizadas com a finalidade de completar sua formação, entre 1925 e 1929, que permitem, no exame da disputa familiar entre a carreira na Companhia de Jesus e na política, discutir as escolhas possíveis a Anísio Teixeira.

A primeira viagem ao exterior seguiu a prática corrente entre algumas famílias ricas de enviar seus filhos para o exterior, de onde deveriam voltar com o domínio de línguas estrangeiras e pinceladas de conhecimento de arte e de literatura capazes de distingui-los de seus colegas de grupos com menores propriedades sociais. A segunda já ocorreu como missão do governo do estado para estudo do sistema educacional norte-americano. Os propósitos, registrado em diário de viagem (Teixeira, 1927), contém o esboço dos usos possíveis das conquistas acumuladas no estrangeiro. A terceira ocorreu com bolsa de estudos oferecida pela Universidade de Columbia onde seu irmão, o engenheiro Oscar S. Teixeira, formado pela Escola Politécnica de São Paulo, fez seus estudos de 1920 a 1922.

As cartas enviadas durante essa viagem contêm, de maneira detalhada, os encontros com protagonistas importantes da futura classe dirigente do Brasil pós-1930, focalizando os momentos e os ambientes que foram decisivos para a redefinição de seus rumos políticos.

\section{Elegante vagabundagem: viagem à Europa}

A viagem pela Europa ${ }^{6}$ ocorre em plena vigência do mandato de inspetor geral do ensino, o que indica um acordo entre a família, os jesuítas e o próprio governo do estado.

Acompanhado por Dom Augusto Álvaro da Silva, arcebispo-primaz do Brasil, Anísio
Teixeira seguiu para Roma por ocasião das comemorações do Ano Santo de 1925 e foi apresentado ao Papa Pio Xl, que vinha de negociar com Mussolini a criação do Estado do Vaticano. A visita impressionou-o favoravelmente em especial pela movimentação de católicos de todo o mundo, testemunhando fidelidade a Roma em meio aos movimentos socialistas e comunistas que se espalhavam por toda a Europa ${ }^{7}$.

Do Vaticano, envolvido em acordos políticos com o nascente movimento fascista, seguiram para Paris, onde se hospedaram em um convento da Companhia de Jesus. 0 programa nessa cidade constou de visita a escolas primárias e participação em debates e conferências na Sorbonne (Lima, 1978). Seu diário de viagem registra um rapaz de 25 anos, marcado pelos colégios jesuitas e pelo desenraizamento. Suas palavras traduzem um pouco de amargor e desesperança, inspiradas também, talvez, pelo complexo período de entre-guerras.

De modo geral devo dizer que o aprendizado foi muito curto e que é muito cedo para tirar conclusões. Sob o lado técnico ganhei evidentemente alguns conhecimentos novos. Sob o lado de formação geral aumentei, é inegável, o meu cabedal de cultura. [...] E a minha fé, a minha compreensão metafísica da vida não está também cada vez mais afastada de mim, como um objeto que eu conservo culto mas de que já não uso? (Teixeira, 1925a)

0 sentimento de solidão é evidenciado nessa primeira viagem ao exterior e revela as dificuldades em apropriar-se de um novo código cultural que impõe outros modos de falar, abordar e circular.

Ter pouco, mas seguro, forte, inarrancável é melhor do que esse brilho de mil facetas de

5. A documentação e bibliografia disponível na Biblioteca Virtual Anísio Teixeira não apresenta numeração de páginas.

6. A viagem aparece documentada em discursos e artigos escritos pelo autor nesse período e no relatório intitulado Anotações de viagem à Europa (1925). 7. TEIXEIRA, Anísio. Paris é um filho espiritual de Roma. Entrevista. A Tarde. Salvador, 30 nov. 1925. 
cores cambiantes com que se enfeita um espírito viajado, brilho fatigante porque lhe falta a profundidade, porque não é luz própria. [...] 0 vago brilhante é o vício a que habituaram quatro meses de elegante vagabundagem pela Europa. Pois bem, tudo não está perdido. Desses quatro meses muita coisa se há de aproveitar. Mas está encerrado o ciclo da vida errante e amável. (Teixeira, 1925a)

Na citação acima, Anísio deixa ver seu espírito de político de ação como será mais tarde conhecido. Tem pressa de voltar, antevê as coisas que tem a fazer na Bahia. Em entrevista ao Jornal "A Tarde", de Salvador, reafirma sua percepção impregnada de um catolicismo conservador.

\section{[...] darei, da Europa, um resumo comovente} e dentro do profundo misticismo da época contemporânea, uma encruzilhada de luz onde se dão rendez-vouz todas as misérias animadas do esplendor de todas as esperanças [...]. (Teixeira, 1925b)

A confrontação desses dois documentos e de mais um terceiro discurso - proferido na inauguração da Escola Normal na cidade de Caetité - permite visualizar os efeitos da viagem no cumprimento do seu destino de político laico ou religioso. A responsabilidade de retornar melhor preparado para a escolha do seu destino profissional se confrontou aí com as estratégias da Igreja Católica para a expansão da fé, com as implicações da guerra e com os avanços da sociedade moderna. A observação sobre Paris nos dois primeiros documentos é significativa do conflito que vivia frente aos seus possíveis caminhos. Ela mostra o pensamento católico e sertanejo herdado no caminho da casa do chefe político à igreja com desvio para o palácio do governo estadual. Só consegue ver Paris como uma Babel cosmopolita.

Quando eu procuro rever Paris e fecho os olhos com energia, num apelo a todas as forças misteriosas da lembrança, gira em minha imaginação um filme singularmente confuso, um filme cujas cenas criadas na dispersão do trabalho preparatório dos estúdios, não fossem postas em ordem, um filme a que faltasse a inteligência organizadora do diretor de cena ou que, por paradoxo, tivesse um "metteur en scène" genial. Todos os planos se confundem como em um pesadelo. 0 real e o imaginário fazem um só par singularmente afetuoso, como na vida. (Teixeira, 1925a)

A viagem à Europa, entretanto, exerceu um triplo efeito sobre o viajante: propiciou o contato com a vida social e política de países centrais; aproximou-o do poder central da lgreja Católica; e permitiu o primeiro dos vários estudos que realizou sobre as experiências educacionais em outros países.

Quanto ao primeiro ponto, a viagem contribuiu para acentuar o conservadorismo fascista que já acometia um grupo de intelectuais baianos. Anísio voltou encantado com o novo Estado do Vaticano, criado com o apoio de Mussolini em troca da simpatia da Igreja Católica aos seus projetos. Da mesma forma, reavivou sua admiração pelo movimento de reação política francês, comandado por Charles Maurras e Léon Daudet, além de Philipe Barres e George Vallois, o qual já se constituía em objeto de discussão de seu grupo de intelectuais, formado por Madureira de Pinho - importante jurista baiano -, Luiz Viana Filho, Hermes Lima e o francês Michel Poncet, que vivia em Salvador.

Em Portugal, visitou o Conde de Mafra, monarquista nostálgico do império português e descendente de uma dinastia de servidores do Rei. Novamente é Anísio influenciado pelo bispo com quem viajava, por personalidades da monarquia católica, contra as ideias socialistas que se espalhavam por toda a Europa nos meados dos anos 1920.

A parte do programa de viagem de interesse do estado baiano só aparece no discurso de inauguração da Escola Normal de Caetité quando o orador aproxima a imagem das professoras normalistas àquela dos missionários e pregadores: 
Vimos installar a Eschola Normal de Caetité, um noviciado de professores e de mestres, que, mais tarde, sahirão pela terra sertaneja a ensinar e a educar. (Teixeira, 1926)

Foi nessa ocasião que mencionou pela primeira vez os sistemas educacionais e as escolas que visitou, além dos grandes pensadores que conheceu ou retomou por ocasião da viagem. 0 inspetor geral do ensino defende a necessidade de educar o povo como forma de garantir o progresso e a civilização da pátria. 0 exemplo da França com sua escola republicana é confrontado com os da Suiça e da Bélgica, para mostrar que, mais do que produção de novas teorias, havia necessidade de uma administração pública capaz de universalizar a escolarização. Assume, assim, no retorno da viagem à Europa, um discurso mais de acordo com o governo do banqueiro e advogado Góis Calmon, do que com o de qualquer pedagogia da Europa liberal ou socialista.

O ensino primario francêz é um modêlo nesta orientação. Enquanto os paizes visinhos se agitam na mais febril das actividades pedagógicas, o velho e sábio organismo do ensino primário francêz espera e aguarda paciente as conclusões definitivas. 0 seu espírito de conservação e a excessiva complexidade da machina escolar garantem a esse organismo um vigor e uma segurança excepcionaes. (Teixeira, 1926)

\section{Viagem aos Estados Unidos: estudos e encontros políticos}

A segunda viagem internacional, dois anos depois, é marcada pela clareza sobre a missão a que se julgava investido como político profissional. Viaja desacompanhado, comissionado pelo estado da Bahia, que dessa vez lhe incumbe uma tarefa precisa: estudar o sistema de educação americano, cujo sucesso, acreditava-se, teria garantido o progresso daquele país. Foi diretamente para Universidade de Columbia, local onde, repetindo palavras de Gilberto Freyre que ali havia estudado, "se encontrava a nata da mocidade estrangeira a preparar-se para se tornar na idade madura 'leaders' em suas terras, 'futuros leaders do mundo" (Pallares-Burk, 2005, p. 167). No caso brasileiro, além de Gilberto Freyre e Oscar Teixeira, haviam passado por essa universidade: Octávio Mangabeira e Afrânio Peixoto, colaboradores, em distintos momentos, no projeto anisiano.

Essa viagem é classificada por Anísio (1927), em seu diário de viagem, escrito ainda a bordo do navio, como uma nova etapa de sua formação. A escrita expressa o temor da solidão já experimentado em sua viagem anterior, associado à ansiedade das descobertas possíveis, razão pela qual, ao imaginar uma Nova York similar à Paris cosmopolita e tumultuada, apega-se à imagem segura do sertão onde deixou família e amigos. Entretanto, é uma imagem que não esconde a certeza de suas capacidades para desvendar o conhecimento que lhe fora antecipado, por meio dos relatos feitos pelo irmão que o antecedeu, pelas observações de seus companheiros de viagem e pela leitura de Henry Ford, o mais importante capitão do progresso americano.

Deixamos de ver terra. Temos somente diante de nós o grande oceano. E muito longe, essa New York tumultuária e colossal. Tão profundamente diferente de tudo que eu conheço. Tão chocante. Caminho para esse mundo novo com uma curiosidade apreensiva e febril. Deixei para ir conhecêla meus amigos, meus livros, meus deveres, minha terra. (Teixeira, 1927)

A observação dos americanos, companheiros de viagem, representa a tentativa de aproximação e de domínio do novo código de convivência. Para que lhe

[...] seja possivel conhecer alguma coisa dessa extraordinária alma americana, se submete a suportar as suas pisadas de soldado em marcha diante de minha cadeira de bordo, as suas ruidosas expansões. (Teixeira, 1927) 
0 processo de socialização e de inserção a que se submete é carregado pela experiência já acumulada no espaço internacional. Ele tinha conhecimento suficiente para manter-se curioso e podia fazer conjecturas do que seria um americano, mas sofria com a diferença de costumes.

A leitura de bordo não foi escolhida ao acaso. Anísio lia My Life and Work de H. Ford e estabelecia um paralelo entre esse pensamento e os de Tomás de Aquino e Ignácio de Loyola, todos plenos de disciplina e de crença na força do trabalho.

Em campos diversos - na vida espiritual, um; na vida industrial, outro; - dois livros deram-me a sensação de plenitude, de profundo acordo, de inexistência de dúvida Os exercícios espirituais de Ignácio de Loyola; My Life and Work de Henry Ford. (Teixeira, 1927)

Seu diário parece destinado a registrar o pensamento anterior à viagem realizada para tomar contato com o "novo mundo". O fragmento seguinte mostra continuidade ao pensamento esboçado nos textos da viagem à Europa. Trata-se de uma reflexão sobre a organização política e sobre o sistema educacional, na qual procura aliar as ideias individualistas e comunitárias dos norteamericanos com o que lhe desagrada no modelo republicano francês, centralizado, que, como nas propostas vindas dos movimentos governistas brasileiros, impedia a liberdade religiosa.

A minha crença política definitivamente se inclinou para os regimes descentralizados, facilitadores do florescimento das energias individuais, e das iniciativas pessoais e que garantam uma exata classificação social. Regime livre e justo. Livre, no sentido de não se coibir, de nenhuma sorte, o desenvolvimento do indivíduo e da família; justo, no sentido de criar uma atmosfera onde os quadros sociais se instalem com sentido do merecimento e do valor. [...] No campo do pensamento ou da religião podemos fazer o que queremos, mas o que nos é dado, pela escola, pelo governo, é feito sob medida positivista ou agnóstica. Não temos a liberdade de escolher. Positivando - o pobre não pode, no Brasil, dar educação católica ao seu filho. É isto uma restrição séria e incontestável. (Teixeira, 1927)

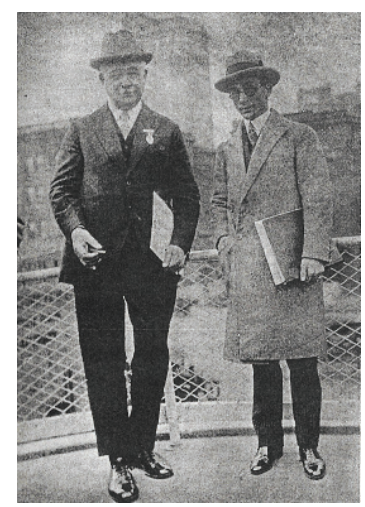

Anísio Teixeira (à dir.) em sua viagem de estudos aos Estados Unidos, tendo ao lado Sebastião Sampaio, cônsul-geral do Brasil em New York. Nova York, 1927. FGV/Cpdoc/Ar. Anísio Teixeira

Nesse estágio, Anísio Teixeira foi um frequentador assíduo da casa do Cônsul Geral do Brasil, onde conheceu alguns dos intelectuais e políticos a quem se aliará para realizar os projetos de Educação nas décadas seguintes. Esse é, por exemplo, o caso de Delgado de Carvalho, que afirma ter sido a casa do cônsul um lugar de encontro das personalidades brasileiras de passagem por Nova York, onde foi apresentado a Anísio Teixeira (Carvalho, 1960) - que circulava, como se vê na foto acima, com desenvoltura entre importantes nomes nacionais no exterior - pelo próprio Sebastião Sampaio ${ }^{8}$.

Além do encontro com personalidades nacionais nessa viagem, deu-se também o encontro com os intelectuais americanos, cujo impacto sobre o pensamento do educador brasileiro produziria um notável impulso em seu projeto de modernização da Educação. John Dewey e William Heard Kilpatrick são os dois mais citados. Anísio (1928) registra, em seu livro Aspectos da Educação Ame-

8. Foto publicada no livro Conversas entre Amigos. Correspondência escolhida entre Anísio Teixeira e Monteiro Lobato. Aurelio Vianna e Priscila Fraiz (dir). Rio de Janeiro: CPDOC, Fundação Cultural da Bahia. 1986. 
ricana, sua fé na democracia, única forma de organização política e social capaz de promover o progresso de um povo e sua admiração por John Dewey que, para ele,

[...] é, na América, o philosopho que mais agudamente traçou as theorias fundamentaes da educação americana. A nenhum outro pensador é dado alli um logar tão saliente na systematização da theoria moderna de educação. (p. 23)

Nesse mesmo livro - quase um relato de viagem -, aparecem alguns dos temas que comporão a agenda dos Pioneiros da Educação Nova, como os métodos de Educação, construção do currículo, a organização escolar e o sistema estatal de Educação. Ele retrata um estudante atento à totalidade do sistema educacional, não descuidando de qualquer dos aspectos concernentes à escolarização, cuja visão expressa alguém que se vê como responsável pela nação, dispondo-se a servir ao Estado. Do recrutamento dos alunos - tema ao qual dedicou um capítulo de seu livro -, ao sistema escolar das pequenas cidades, até o órgão federal de Educação americana, tudo foi submetido à minuciosa apreciação, e o estudante partiu muito bem impressionado e com planos de retornar para mais estudos.

Ao chegar à Bahia no final de 1927, retoma suas atividades na Inspetoria de Instrução Pública, segue, todavia, enfrentando rumores de que logo partirá para o noviciado jesuíta, ideia alimentada no jornalismo político.

\section{Segunda viagem aos Estados Unidos: preparação técnica e alianças intelectuais}

Este foi um período extraordinariamente significativo em minha vida, que eu iniciei com o conhecimento de Lobato que se encerra com o conhecimento de V. no Rio entre junho de 1928 e junho de 1929. Tenho a impressão que foi neste ano que eu me encontrei comigo mesmo. 0 ano de estudos na Columbia
University, a descoberta de J. Dewey, a revisão (ou reconversão?) filosófica e as grandes amizades intelectuais - Lobato, Fernando, Lourenço, Afrânio Peixoto e muitos outros. (Vidal, 2000, p. 132)

Nesse período, Anísio acentua o valor de suas viagens anteriores e a capacidade de adaptação aos novos tempos políticos do mundo, propiciadas pela sua socialização pelas afinidades eletivas que aproximam os agentes dotados de habitus ou gostos produzidos por condições e condicionamentos semelhantes.

Contando certamente com uma carta de recomendação de Octávio Mangabeira, Ministro das Relações Exteriores do Brasil, Anísio foi recebido em Nova York por Monteiro Lobato, Adido Comercial do Brasil. Juntos visitaram as indústrias da Ford que impressionaram os dois estrangeiros em terras norte-americanas ${ }^{9}$. As afinidades se transformam em amizade e desempenham importante papel na inserção de Anísio Teixeira em espaços sociais e políticos primeiramente nos EUA, depois em São Paulo e no Rio de Janeiro, considerando todos os laços de Monteiro Lobato com a elite cafeeira paulista, bem como com os políticos e intelectuais paulistas e sua famosa editora.

A estadia em NY mostra bem o que difere uma viagem cultural de filho bem educado pelas elites, de outra que visa o estudo numa universidade, com bolsa e projeto bem estabelecido. No ano acadêmico de 1928/1929, Anísio Teixeira dedicou-se aos estudos de filosofia e educação, concluindo com brilhantismo seu Master of Art, sempre com um olho voltado para seu posto burocrático na Bahia. Dizia em carta a seu substituto:

Eu, com sete diferentes cursos, estou lutando como posso para dar conta da matéria. Quero obter facilidades para trabalhar para aí. Continuo no propósito de escrever um

9. Monteiro Lobato traduziu os livros de H. Ford: Os princípios da prosperidade, publicado no Rio de Janeiro pela Brand, s/d; Minha vida minha obra, publicado em 1925 pela Graphico - Monteiro Lobato. 
text-book de educação. Que me diz? E ainda organizar um plano de ensino normal. (Pereira Guimarães, 1982, carta 11/10/1920)

Nessa mesma correspondência, ele comenta a campanha presidencial de Herbert Hoover, ressaltando a importância do rádio nos períodos eleitorais que permite aos candidatos o acesso democrático a seus eleitores. Todavia, não apenas a política americana lhe interessava: estava atento a todas as possibilidades que estar na Universidade de Colúmbia the oferecia. Ele acompanhava as políticas educacionais de distintos países e irritava-se ao comparar os investimentos em Educação nos EUA, nas Filipinas e na própria universidade que frequenta, com as minguadas dotações orçamentárias da Bahia (Pereira Guimarães, 1982).

Depois de algum tempo, Anísio, começa a perceber as mudanças que se operam nas suas concepções políticas como se observa no seguinte trecho de outra carta.

[...] estou a reconstituir toda a minha filosofia, dirigindo-a para caminhos que me afastarão muito provavelmente até do próprio catolicismo. 0 trabalho que vem passando a minha inteligência, desde a minha primeira viagem à América e o seu pragmatismo, ainda não está terminado. (Pereira Guimarães,1982, carta de 07/11/1928)

Talvez por esta razão, ele não perde de vista o desenrolar da política baiana. Escreve regularmente pedindo notícias e fornecendo orientações ao seu substituto. Opina sobre mudanças na pasta, especialmente sobre nomeações e dispensa de pessoal. Escreve também regularmente ao governador Góis Calmon e a outros membros do governo. Ao mesmo tempo, não mede esforços para conquistar um lugar no espaço internacional começando por ensaiar a publicação de pequenas notas sobre o Brasil na imprensa americana.

Insisto para que V. me mande uma notícia da Semana de Educação (pela qual eu o felicito vivamente), em inglês, para eu encami- nhar à National Education Association. (Pereira Guimarães, 1982, carta de 11/10/1928)

Em seu retorno ao Brasil, conta novamente com uma carta de apresentação, agora de Monteiro Lobato a Fernando de Azevedo, naquele momento Diretor de Instrução Pública do Distrito Federal, ligado ao jornal 0 Estado de São Paulo. A carta de Lobato será uma chave importante para abrir as portas de acesso aos grupos políticos de São Paulo e do Rio de Janeiro, uma vez que era dirigida a um destacado membro do "liberalismo oligárquico" representado pelo jornal paulista.

Fernando. Ao receber esta para! Bota para fora qualquer Senador que te esteja aporrinhando. Solta o pessoal da sala e atende o apresentado, pois ele é o nosso grande Anísio Teixeira, a inteligência mais brilhante e o maior coração que já encontrei nestes últimos anos de minha vida. 0 Anísio viu, sentiu e compreendeu a América e aí te dirá o que significa esse novo fenômeno no mundo. (Vianna Filho, 1990, s/p)

Do Rio de Janeiro, Anísio Teixeira segue para a Bahia onde encontra seu campo minado em função da situação política do país que dividiu sua família entre os que apoiavam as forças nacionais ligadas a Getúlio Vargas e os que, como seu pai, apoiavam as oligarquias dos Góis Calmon.

Quando deixou a Bahia, um ano antes, Anísio, tinha como certa a eleição a deputado federal que se perdeu em meio à revolução de 1930 e a subida de Getúlio Vargas ao poder nacional. 0 pai insistia nessa via, mas Anísio, entre os sentimentos e valores morais tradicionais e o moderno mundo da democracia e do capitalismo, escreve ao pai dando conta das mudanças que se haviam operado.

Quanto a mim as promessas são sempre grandes... Dizem que a minha candidatura era justíssima. Papai precisa não esquecer 
que nestas ocasiões v. mecê volta a ser corrente política e a mais verdadeira e tradicional do Estado... Entretanto para os direitos da política, nem sempre contam conosco. Enfim dizem que me reservam a Secretaria do Interior no Governo Vital em que dirigirei a política do sertão, serei o sucessor político de Vmecê... (Vianna Filho, 1990)

Em meados de 1930, de volta à Capital Federal, Anísio Teixeira reexamina suas relações à luz de seu passado e encontra entre outros o conterrâneo de Caetité, Nestor Duarte - que se tornou célebre pela sua, até hoje imprescindivel obra, A ordem privada e a ordem política, um clássico do pensamento político brasileiro - que Ihe apresentou Emilia Ferreira, com quem se casaria, realizando uma fecunda aliança familiar com o próprio Nestor Duarte, casado com uma irmã de Emilia. As três famílias - Teixeira, Ferreira e Duarte - eram originárias do sertão baiano.

$\mathrm{Na}$ Capital Federal, Anísio começa ensinando na Escola Normal, entretanto, vem de posse de competências susceptíveis de lhe assegurarem um lugar conveniente nos planos do novo governo. Seus estudos acumulados em instituições consideradas de excelência no exterior lhe valeriam uma posição privilegiada na concorrência com outros indivíduos de formação local.

\section{Novos rumos de uma carreira bloqueada: a Educação Nacional}

Na nova fase, Anísio Teixeira contará, no Brasil e no exterior, com a rede de relações sociais que construiu ao longo dos seus anos de carreira, aliadas àquelas herdadas da família. Por meio de Fernando de Azevedo, reencontra Afrânio Peixoto, afilhado de sua mãe, médico e escritor célebre por sua obra científica e literária no país e no exterior, que o apresenta a Venâncio Filho, presidente da Associação Brasileira de Educação - ABE - e a Pedro Ernesto, político ligado ao movimento tenentista (1922-1934), colaborador da Aliança Nacional Libertadora $\mathrm{ANL}-$, indicado pelo governo revolucionário a
Interventor do Distrito Federal. Themístocles Cavalcanti - ex-colega de turma na Faculdade de Direito (1920/1922), amigo do Ministro Francisco Campos - sugere seu nome para participar da reorganização do Ensino Secundário.

Afrânio Peixoto e Pedro Ernesto passaram pela Faculdade de Medicina da Bahia onde provavelmente estiveram com membros da família de Anísio Teixeira que ali estudaram como o deputado Cesar Zama ou o próprio Deocleciano Teixeira.

Assim, em 1931, Anísio Teixeira é convidado para a Diretoria da Instrução Pública do Distrito Federal no espaço de poder nacional (Paim, 1982). Essa diretoria, anteriormente comandada por Fernando de Azevedo, situavase no coração das disputas pela Educação Nacional, e Anísio estava convencido disso como escreveu ele a Fernando de Azevedo:

[...] creio já lhe haver dito que é minha impressão não ser possível travar, no Brasil, a batalha educacional, antes de vencermos a peleja do Distrito Federal. (Vidal, 2000, p. 22)

Na ordem política instaurada após 1930, a educação foi alçada à condição de problema nacional com a criação de um ministério próprio (Schwartzman et al. 1984). Nesse mesmo ano, Anísio Teixeira passa de professor na Escola Normal ao posto de diretor de Instrução Pública da capital federal e tem a oportunidade para demonstrar suas experiências com o individualismo americano e as instituições democráticas como se pode verificar no livro que ele escreveu em 1934 (Schwartzman et al., 1982). Ele estaria propenso a incorporar as novas contribuições adquiridas nas viagens ao primeiro mundo (Chagas, 2000). Ele próprio provara amostras de seu potencial em escritos nos quais está presente a influência de suas viagens, de John Dewey em especial, quando repensa as instituições políticas no Brasil em construção no período revolucionário.

Desta sorte, a democracia americana presuppõe tres factos fundamentaes: a) que todos os homens têm completo direito a 
uma perfeita participação nas formas mais altas de vida social, o que envolve direito, a egual opportunidade economica e egual opportunidade educativa; b) que a vida neste planeta está sujeita ás leis ordinarias de evolução, sendo a progressiva libertação do homem, dentro das suas condições naturaes de vida, uma questão de esforço, de experiencia e de ascencional ajustamento; c) que o homem, pela largueza do seu coefficiente de educabilidade e pelo seu poder de controle sobre as causas naturaes que lhe dá o conhecimento, vae-se tornando, cada vez mais, senhor e juiz do seu destino na terra. (Teixeira, 1934, p. 14)

Durante quatro anos na Educação do Distrito Federal, com o apoio de Pedro Ernesto, Anísio encontrou as condições para dar início ao seu programa de reconstrução nacional, assentado no caráter do projeto político de modernização conservadora, que já vinha sendo desenvolvido com Oliveira Viana, Alberto Torres, entre outros (Vieira, 1976). As suas ideias de substituir o poder parlamentar pela constituição de conselhos técnicos, como expressou em carta a Monteiro Lobato, já eram bem conhecidas:

Quando veremos que o problema de organização, e não o problema político é o que realmente importa? Preparem-se os homens. Criem-se os técnicos. Eles organizarão. Da organização virá a riqueza. E tudo mais política sã, liberdades etc. etc. - virá de acréscimo. (Vianna; Fraiz, 1986, p. 56)

Dessa maneira, não é surpreendente que ele tenha sido um dos mais dedicados debatedores do capítulo da Educação na Constituição de 1934, enfrentando notáveis confrontos políticos como ele mesmo declara em outra carta a Fernando de Azevedo. "O capítulo da Constituinte contém o máximo que podia, no momento, triunfar entre nós" (Vidal, 2000, p. 27).

$\mathrm{Na}$ sua administração, o Instituto de Educação projetado para ser uma escola normal modelo, passou a funcionar como laboratório para as políticas públicas do novo governo. Fundou também o Instituto de Pesquisas Educacionais cuja função era, entre outras, recolher dados sobre a realidade educacional do Distrito Federal que servissem de subsídio às ações educacionais (Mariani, 1982).

A culminância do projeto de organização política da nação com base na competência técnica foi a criação da Universidade do Distrito Federal - UDF -, como escreve Simone Meucci (2006), baseada na crença de que a universidade

[...] poderia efetivamente colaborar para uma coordenação intelectual que irradiasse o conhecimento humano entre diferentes camadas da sociedade. Uma coordenação universitária evitaria o autodidatismo, o conhecimento como mero fator de diferenciação social, o isolamento dos intelectuais, a segregação cultural da população. (p. 117)

Tratava-se de uma universidade para a formação de quadros para o estado e de professores para as escolas públicas. A pesquisa deveria servir à máquina pública e ao ensino.

Tal projeto estava apoiado sobre contratações de intelectuais brasileiros com formação técnica semelhante à de Anísio Teixeira, vindos de estados periféricos como é o caso da Bahia e de Pernambuco e não pertencentes às antigas oligarquias instaladas na capital federal. $\mathrm{Na}$ lista de professores brasileiros, destacam-se: Candido Portinari, Delgado de Carvalho, Gilberto Freyre, Heitor Villa-Lobos, Heloísa Alberto Torres, Josué de Castro, Sérgio Buarque de Holanda. Os professores estrangeiros foram escolhidos na Sorbonne, no College de France e em Strasburgo.

Anísio Teixeira, embora seduzido pelo progresso e industrialismo americano e convencido de que nesse modelo político e econômico estava a solução para os problemas brasileiros, não conseguiu abandonar a imagem da Europa, especialmente da França, como o ideal de educação e cultura e só contrataria missões 
científica e culturais nos Estados Unidos depois da Segunda Guerra Mundial, quando novamente foi secretário de Educação na Bahia. A partir de então, nos anos 1950, sua política para a Educação no Brasil, desenvolvida por meio da CAPES, do INEP e do Centro Brasileiro de Pesquisas Educacionais - CBPE - contaria com a colaboração crescente de intelectuais e instituições norte-americanas e com a UNESCO.

Pedro Ernesto e Anísio Teixeira mantinham proximidade da Aliança Nacional Libertadora - ANL - , uma frente política que reunia setores de esquerda em torno do combate ao fascismo e ao imperialismo. Anísio Teixeira publicava artigos no jornal oficioso da ANL e acabou sendo acusado de envolvimento no levante comunista promovido por essa organização em 1935. Tais fatos obrigaram Pedro Ernesto a afastá-lo de seu governo.

Durante a ditadura Vargas - 1937-1945 - Anísio Teixeira, permanecerá afastado do poder e da Educação, refugiado na Bahia onde se ocupará dos negócios de mineração e exportação herdados da família. Servindo-se dos conhecimentos acumulados em seus estágios internacionais, assume a direção de empresas estabelecidas em sociedade com empresários norte-americanos do setor de minérios. Nessa atividade, amplia ainda mais sua rede internacional para voltar depois de uma década ao centro do poder nacional, traçando a política desenvolvimentista para a Educação.

\section{Referências bibliográficas}

CARVALHO, D. Anísio, Vulcão de ideias. In: AZEVEDO, F. de (Dir.). Anísio Teixeira: pensamento e ação. Rio de Janeiro: Civilização Brasileira, 1960. Disponível em: <http://www.prossiga.br/anisioteixeira/>. Acessado em:10 mar. 2008.

LIMA, H. Anísio Teixeira: estadista da educação. Rio de Janeiro: Civilização Brasileira, 1978. Disponível em: <http://www.prossiga.br/ anisioteixeira/>. Acessado em:10 mar. 2008.

MEUCCI S. Gilberto Freyre e a sociologia no Brasil: da sistematização à constituição do campo científico. 2006. 349 p. Tese (Doutorado em Sociologia)- UNICAMP, Campinas, 2006.

PAIM A. Por uma universidade no Rio de Janeiro. In: SCHWARTZMAN, S. (Dir). Universidade e instituições científicas no Brasil. Rio de Janeiro: CNPq, 1982. p.17-96.

PALLARES-BURK, M. Gilberto Freyre um vitoriano dos trópicos. São Paulo: Ed. Unesp, 2005.

PANG, E. Coronelismo e oligarquias 1889-1943: a Bahia na Primeira República brasileira. Rio de Janeiro: Civilização Brasileira, 1979.

SCHWARTZMAN, S. (Org.). Universidade e instituições científicas no Brasil. Rio de Janeiro: CNPq, 1982.

SCHWARTZMAN, S.; BOMENY, H.M.B.; COSTA, V.M.R. Tempos de Capanema. Rio de Janeiro: Paz e Terra; São Paulo: Editora da Universidade de São Paulo, 1984.

TEIXEIRA, A. Aspectos da educação americana. Salvador: Tip. de São Francisco, 1928. Disponível em: <http://www.prossiga.br/ anisioteixeira/>. Acessado em:10 mar. 2008.

Em marcha para a democracia a margem dos Estados Unidos. Rio de Janeiro: Guanabara, s/d. Disponível em: <http:/ /www.prossiga.br/anisioteixeira/>. Acessado em:10 mar. 2008.

VIANNA FILHO, L. Anísio Teixeira: a polêmica da educação. Rio de Janeiro: Nova Fronteira, 1990. Disponível em: <http:// www.prossiga.br/anisioteixeira/>. Acessado em:10 mar. 2008. 
VIANNA, A. ; FRAIZ, P. (Orgs.) Conversas entre amigos correspondência escolhida entre Anísio Teixeira e Monteiro Lobato. Rio de Janeiro: CPDOC; Fundação Cultural da Bahia, 1986.

VIDAL, D. (Org.). Na batalha da educação: correspondência entre Anísio Teixeira e Fernando Azevedo (1929-1971). São Paulo: IEB; CDAPH-IFAN; USF, 2000.

VIEIRA, E. Oliveira Vianna e o Estado corporativo. São Paulo: Grijalbo, 1976.

\section{Fontes}

PEREIRA GUIMARÃES, A. Dois sertanejos baianos do século XX. Salvador, Universidade Federal da Bahia, 91 p., 1982. Disponível em: <http://www.prossiga.br/anisioteixeira/>. Acessado em:10 mar. 2008.

TEIXEIRA, A. A propósito da "Escola Única". Revista do Ensino. Salvador, v. 1, n. 3, 1924. Disponível em: <http://www.prossiga.br/ anisioteixeira/>. Acessado em:10 mar. 2008.

. Anotações de viagem à Europa. Lisboa: FGV/CPDOC, 1925a. Disponível em: <http://www.prossiga.br/anisioteixeira/> . Acessado em:10 mar. 2008.

Anotações de viagem aos Estados Unidos. Navío Pan American: FGV/CPDOC, 1927. Disponível em: <http:// www.prossiga.br/anisioteixeira/>. Acessado em:10 de mar. de 2008.

0 alto sertão da Bahia. Revista do Instituto Geographico e Historico da Bahia. Salvador, v.52, p. 295-309, 1926. Disponível em: <http://www.prossiga.br/anisioteixeira/>. Acessado em:10 mar. 2008.

.Paris é um filho espiritual de Roma. Entrevista. A Tarde. Salvador, 30 nov. 1925b. Disponível em: <http://www.prossiga.br/ anisioteixeira/>. Acessado em:10 mar. 2008.

Recebido em 06.05.08

Aprovado em 30.10 .08

Agueda Bernardete Bittencourt, pedagoga pela UFP, mestrado e doutorado em Educação pela UNICAMP, pós-doutorado pela École Normale Supérieure de Fontenay e École des Hautes Études en Sciences Sociales, é conferencista na Universidad Pedagógica Nacional e professora da UNICAMP e tem como linha de pesquisa: cultura, política e educação. 